Article

\title{
Numerical Investigation of a Short Polarization Beam Splitter Based on Dual-Core Photonic Crystal Fiber with $\mathrm{As}_{2} \mathrm{~S}_{3}$ Layer
}

\author{
Nan Chen ${ }^{1}{ }^{1}$, Xuedian Zhang ${ }^{1,2, *}$, Xinglian Lu ${ }^{1}$, Zheng Zhang ${ }^{1}$, Zhangjian Mu ${ }^{1}$ and \\ Min Chang ${ }^{1}$ \\ 1 Key Laboratory of Optical Technology and Instrument for Medicine, Ministry of Education, \\ University of Shanghai for Science and Technology, Shanghai 200093, China; \\ cn15800968586@163.com (N.C.); 151360021@st.usst.edu.cn (X.L.); zhangzheng2010370@163.com (Z.Z.); \\ 18795901552@163.com (Z.M.); changmin@usst.edu.cn (M.C.) \\ 2 Shanghai Key Laboratory of Molecular Imaging, Shanghai University of Medicine and Health Sciences, \\ Shanghai 201318, China \\ * Correspondence: xdzhang@usst.edu.cn
}

Received: 21 June 2020; Accepted: 20 July 2020; Published: 21 July 2020

\begin{abstract}
A polarization beam splitter is an important component of modern optical system, especially a splitter that combines the structural flexibility of photonic crystal fiber and the optical modulation of functional material. Thus, this paper presents a compact dual-core photonic crystal fiber polarization beam splitter based on thin layer $\mathrm{As}_{2} \mathrm{~S}_{3}$. The mature finite element method was utilized to simulate the performance of the proposed splitter. Numerical simulation results indicated that at $1.55 \mu \mathrm{m}$, when the fiber device length was $1.0 \mathrm{~mm}$, the $\mathrm{x}$ - and y-polarized lights could be split out, the extinction ratio could reach $-83.6 \mathrm{~dB}$, of which the bandwidth for extinction ratio better than $-20 \mathrm{~dB}$ was $280 \mathrm{~nm}$. It also had a low insertion loss of $0.18 \mathrm{~dB}$ for the x-polarized light. In addition, it can be completely fabricated using existing processes. The proposed compact polarization beam splitter is a promising candidate that can be used in various optical fields.
\end{abstract}

Keywords: polarization beam splitter; photonic crystal fiber; extinction ratio; insertion loss; fabrication

\section{Introduction}

A polarization beam splitter [1] (PBS) is an extremely common optical device in optical fiber communication, optical fiber sensing, and optical measuring systems that can split an incident light into two orthogonally polarized lights that constitute a fundamental mode (FM). Usually, a PBS can also be applied in reverse as a beam combiner (BC). Nowadays, there are many waveguides to achieve the polarization beam splitting effect, such as those of the prism, planar waveguide, photonic crystal, metasurface, and optical fiber [2-6]. Among them, fiber-based PBS research is very popular due to its integrability and low cost. However, conventional fibers have an insufficient design flexibility and are glass-based, which is not suitable for excessive processing. Thus the performance of PBSs using conventional fibers as carriers is greatly restricted.

In recent years, photonic crystal fibers (PCFs) have been found to overcome the shortcomings of traditional optical fibers and to greatly broaden the fiber research field. PCFs are widely popular because they have special transmission mechanisms, and their optical properties can be enriched by tailoring the arrangement of internal capillary rods $[7,8]$. Compared with conventional fibers, PCFs have the unique properties of endless single-mode (ESM) transmission, high birefringence (HB), a large mode area (LMA), and tunable dispersion, so PCFs can be utilized as excellent carriers for in-fiber PBSs. Apart from PBS, common applications include couplers [9] and sensors [10]. Generally, there are 
two kinds of in-fiber PBSs: One is used to achieve the beam splitting phenomenon by breaking the core symmetry of PCFs for producing the $\mathrm{HB}$ effect, and the other is the use of modulation by filling some functional materials into PCFs.

The appearance of PCFs provides the possibility to design new types of in-fiber PBSs. Thus far, scholars have proposed many novel PCF-PBSs. For instance, in 2009, Hameed et al. proposed a PBS based on soft glass PCFs with nematic liquid crystal (LC), and the PBS of a length of $8.227 \mathrm{~mm}$ had a cross-talk (CT) of better than $20 \mathrm{~dB}$ with bandwidths of $30 \mathrm{~nm}$ (TE mode) and $75 \mathrm{~nm}$ (TM mode) [11]. In 2011, Zhang et al. created a single-mode single-polarization (SMSP) PCF-PBS by introducing two cores into the SPSM PCF, could can realize the splitting of two communication windows at 1.3 and $1.55 \mu \mathrm{m}$ [12]. In 2012, Liu et al. proposed a tellurite glass, three-core PCF-PBS with an 8.7983-mm-long splitter; it had an extinction ratio (ER) of better than $-20 \mathrm{~dB}$ and a bandwidth of $20 \mathrm{~nm}$ [13]. In 2013, Sun et al. proposed a dual-core PCF with a metal wire placed into the cladding air hole between the two cores based on the surface plasmon resonance (SPR) effect; the splitter possessed an ER of $-20 \mathrm{~dB}$ with a bandwidth of $146 \mathrm{~nm}$ [14]. In 2014, Chen et al. proposed a novel PBS based on a dual-core PCF with an LC modulation core that had an ultra-broad bandwidth of $250 \mathrm{~nm}$ with an ER of better than $-20 \mathrm{~dB}$ [15]. In 2015, Xu et al. proposed a dual-core PCF with a length of $0.401 \mathrm{~mm}$; here, the ER could reach $110.1 \mathrm{~dB}$ at $1.55 \mu \mathrm{m}$, and the bandwidths of the ER over 20 and $10 \mathrm{~dB}$ could be as wide as 140 and $200 \mathrm{~nm}$, respectively [16]. In 2017, Wang et al. proposed a tunable PBS filled with magnetic fluids (MFs) in air holes; its length was $8.13 \mathrm{~mm}$, and the polarized mode converted at a magnetic intensity of $25 \mathrm{mT}$ with a high ER greater than $-100 \mathrm{~dB}$. The tunable PBS could work well at temperatures in the range of $0-55^{\circ} \mathrm{C}$ by adjusting the magnetic field strength [17]. In 2018, Younis et al. proposed an asymmetric dual-core PCF, wavelength-selective PBS that can be tuned to split out the $\mathrm{x}$ - and y-polarized modes at wavelengths of 1.3 and $1.55 \mu \mathrm{m}$ [18].

From these PBSs described above, the dual-core PCF is commonly selected as an in-fiber PBS, and the method of filling functional materials such as precious metals, LCs, and MFs into PCFs for generating mode modulation effects is prevalent. In fact, there are many functional materials available for filling PCFs such as rare gases $(\mathrm{He}, \mathrm{Ne}$, and $\mathrm{Ar})$, molecular solids $\left(\mathrm{H}_{2}, \mathrm{CH}_{4}, \mathrm{~N}_{2}\right.$ and $\left.\mathrm{O}_{2}\right)$, and some ionic $(\mathrm{LiH})$, covalent (graphite), and metallic ( $\mathrm{Li}$ and $\mathrm{Mg}$ ) crystals [19]. The performance of these described PBSs based on the modulation of functional materials is very excellent, and they simultaneously possess a compact size, a higher ER, and a wider bandwidth. Based on these design concepts, we intend to propose a simple-structure, dual-core PCF by coating a ring film with a high refractive index (RI) material- $\mathrm{As}_{2} \mathrm{~S}_{3}$-that acts as a PBS. This PCF could be used in the optical fiber communication and sensing field. In our work, the highly applicable finite element method (FEM) [20] was employed to analyze the performance of the compact PCF-PBS by adjusting the structural parameters. Additionally, it is worth mentioning that the proposed PBS can be completely manufactured by modern processes.

\section{Modeling and Theory}

Figure 1a displays the cross-section of the designed PCF-PBS. All air holes were arranged in a hexagonal lattice. The lattice pitch is expressed by $\Lambda$, and there were only two sizes of air holes, $d_{1}\left(d_{1}=1.1 \mu \mathrm{m}\right)$ and $d_{2}$. Additionally, $d_{2} / d_{1}=\alpha\left(\alpha\right.$ is the relative diameter ratio). A thin layer of $\mathrm{As}_{2} \mathrm{~S}_{3}$ film was deposited in the central air hole, of which the thickness can be expressed by $t$. The RI of the air was set to 1 . The fluoride phosphate (FP) N-FK51A glass was selected as the background material in our design, and its Sellmeier model $[21,22]$ in the investigated wavelength range $(1.40-1.75 \mu \mathrm{m})$ can be given by:

$$
n_{N-F K 51 A}^{2}(\lambda)=1+\frac{A_{1} \lambda^{2}}{\lambda^{2}-B_{1}}+\frac{A_{2} \lambda^{2}}{\lambda^{2}-B_{2}}+\frac{A_{3} \lambda^{2}}{\lambda^{2}-B_{3}}
$$

where $A_{1}=0.971247817, A_{2}=0.219014, A_{3}=0.9046517 ; B_{1}=0.00472302 \mu \mathrm{m}^{2}, B_{2}=0.01535756 \mu \mathrm{m}^{2}, B_{3}$ $=168.68133 \mu \mathrm{m}^{2}$, and $\lambda$ is the operating wavelength in the vacuum (in $\mu \mathrm{m}$ ). 


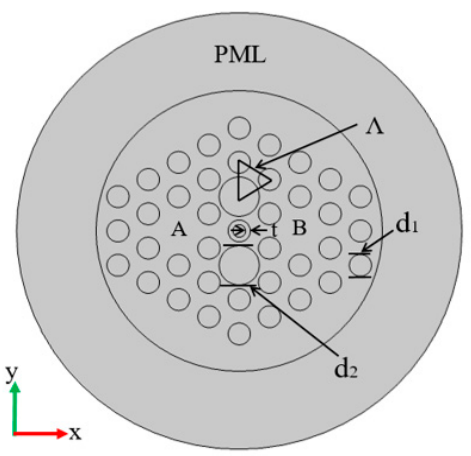

(a)

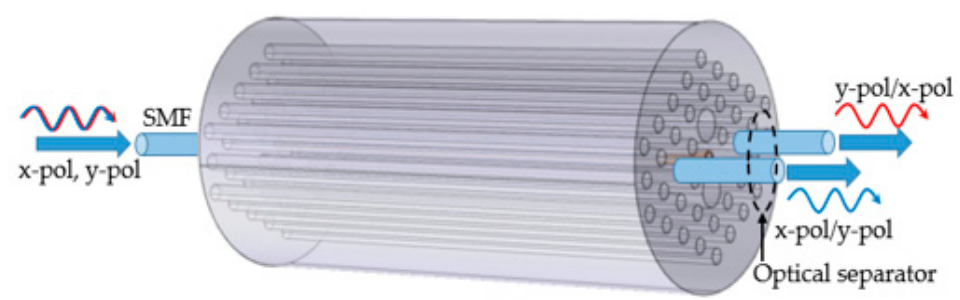

(b)

Figure 1. (a) Cross-section of the proposed photonic crystal fiber-polarization beam splitter (PCF-PBS). (b) Schematic diagram of the PBS operation, where an incident light with the $\mathrm{x}$ - and $\mathrm{y}$-pol modes enters the input port, and the $\mathrm{x}$ - and $\mathrm{y}$-pol modes can be split out at the output port.

$\mathrm{As}_{2} \mathrm{~S}_{3}$ was selected for the proposed PBS for two reasons. One was its high RI, because a higher RI shows a stronger binding effect on light than the background material. The other reason was its simple deposition process, because the solution-processed $\mathrm{As}_{2} \mathrm{~S}_{3}$ glass approach has distinctive virtues over other deposition techniques [23]. Due to the ring structure, special ring modes (RMs) appear on the $\mathrm{As}_{2} \mathrm{~S}_{3}$ ring that can be utilized to generate a mode resonance with the dual-core FM for mode classification. The RI of the $\mathrm{As}_{2} \mathrm{~S}_{3}$ layer in the central hole can also be determined by a Sellmeier equation [24]:

$$
n_{A s_{2} S_{3}}^{2}(\lambda)=1+\frac{D_{1} \lambda^{2}}{\lambda^{2}-E_{1}^{2}}+\frac{D_{2} \lambda^{2}}{\lambda^{2}-E_{2}^{2}}+\frac{D_{3} \lambda^{2}}{\lambda^{2}-E_{3}^{2}}
$$

where $D_{1}=1.898, D_{2}=1.922, D_{3}=0.876, E_{1}=0.022 \mu \mathrm{m}^{2}, E_{2}=0.0625 \mu \mathrm{m}^{2}$, and $E_{3}=0.1225 \mu \mathrm{m}^{2}$.

The effective RI and the mode field distributions for the proposed PBS were solved numerically with the commercial COMSOL5.2 software using the FEM solver. Meanwhile, a perfect matching layer (PML) of $5 \mu \mathrm{m}$ and a scatter boundary condition (SBC) were set at the outermost layer to improve the accuracy of calculations [25] for the 2D simulation. After doing a discrete transform of the proposed structure using a free triangle mesh, we found 176 vertex elements, 1170 boundary elements, and 18,408 elements in the $x-y$ plane region.

We needed to investigate several main PBS performance parameters. The conventional coupling characteristics of a direction coupler based on a dual-core fiber can be employed to calculate coupling length [12]. The coupling length $L_{c}$ is defined by:

$$
L_{c}=\frac{\pi}{\left(\beta_{i}^{\text {even }}-\beta_{i}^{\text {odd }}\right)}=\frac{0.5 \lambda}{\left(n_{i}^{\text {even }}-n_{i}^{\text {odd }}\right)}
$$

where $i=x, y$ and $\beta_{i}^{\text {even }}$ and $\beta_{i}^{\text {odd }}$ represent the propagating constants of the odd and even modes for the $\mathrm{x}$ - and $\mathrm{y}$-polarization ( $\mathrm{x}$ - and $\mathrm{y}$-pol) modes, respectively.

Figure $1 b$ displays schematic diagram of the PBS operation. An incident light carrying the $x$ - and y-pol modes entered the input port with a single mode fiber (SMF). Then different polarized lights 
were output through different cores with the optical separator. Based on these, we assumed that the light was propagating upon core A. The periodic normalized powers [18] at the output side of cores A and B can be calculated by:

$$
\begin{aligned}
& P_{\text {out }}^{A}=P_{\text {in }} \cos ^{2}\left(\frac{\pi}{2} \frac{z}{L_{i}^{c}}\right) \\
& P_{\text {out }}^{B}=P_{\text {in }} \sin ^{2}\left(\frac{\pi}{2} \frac{z}{L_{i}^{c}}\right)
\end{aligned}
$$

where $P_{\text {in }}$ denotes the input light power assumed to be $1, z$ denotes the propagation length, and $L_{i}^{c}$ denotes the coupling length for the $\mathrm{x}$ - and y-pol modes. According to the coupled mode theory (CMT) [26-31], the two polarization states launched into one core of a dual-core PCF can be separated at a specified wavelength when the coupling length of $x$ - and $y$-pol states satisfies the coupling length ratio (CLR) [32]. The CLR can be defined by:

$$
C L R=m / n=L_{x} / L_{y}
$$

where $m / n$ is equal to even/odd or odd/even. It can be considered that after propagating a length of $m L_{x}$ or $n L_{y}$ in a PBS, two lights with different wavelengths will exit through the A and B out ports.

By implementing an accurate electromagnetic field analysis, the performance of the proposed PBS—comprising the CLR, normalized powers, the ER, and insertion loss (IL)—was investigated.

\section{Simulation Results and Analysis}

When an incident light was transmitted in the proposed PBS, two RMs and four core FMs were investigated, as shown in Figure 2. At the interface between the $\mathrm{As}_{2} \mathrm{~S}_{3}$ layer and the substrate material, the $x-R M$ and $y-R M$ were generated, as shown in Figure $2 a, b$, respectively. Figure $2 c-f$ show the even mode in $x$-polarization ( $x$-pol EM), the even mode in y-polarization (y-pol EM), the odd mode in $x$-polarization (x-pol OM), and the odd mode in y-polarization (y-pol OM), respectively, at $1.55 \mu \mathrm{m}$. The introduction of a high $\mathrm{RI} \mathrm{As} \mathrm{S}_{2} \mathrm{~S}_{3}$ film resulted in a stronger optical coupling between the core FMs, which could change the coupling characteristics of the PCF. It could also be observed that the RM and the FM only coexisted in Figure 2e,f. This phenomenon was similar to the SPR effect between $x$ - and y-pol FMs and the specific second-order surface plasmon polariton (SPP) mode [33-35]. The proposed PBS supported two pairs of $\mathrm{RI}$ matching between the $\mathrm{RM}$ on the $\mathrm{As}_{2} \mathrm{~S}_{3}$ film, the core FM could be satisfied at $1.55 \mu \mathrm{m}$, and the energy of the core-guided odd mode could couple into the surface of the $\mathrm{As}_{2} \mathrm{~S}_{3}$ film. The operation principle of this PBS can be explained on the basis of the modal analysis of the dual-core PCF.
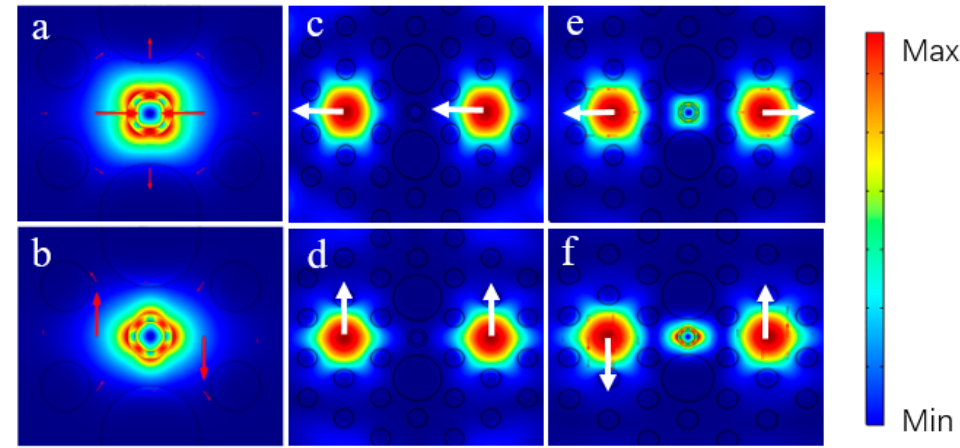

Figure 2. Electric field distributions of the fundamental modes (FMs) for the proposed PCF-PBS at $1.55 \mu \mathrm{m}$. (a) The $x$-polarization ring mode $(x-R M)$, (b) the y-polarization ring mode (y-RM), (c) the $x$-polarization even mode (x-pol EM), and (d) the y-polarization even mode (y-pol EM); the resonance state between the (e) $x-R M$ and the x-polarization odd mode (x-pol OM) and the (f) $y-R M$ and the y-polarization odd mode (y-pol OM). 


\subsection{Birefringence and Coupling Length Ratio}

Usually, an excellent fiber-based PBS is mainly characterized by the HB effect and a short coupling length. Because of $\mathrm{HB}$, the $\mathrm{x}$ - and $\mathrm{y}$-polarization modes in the same core FM cannot easily degenerate, a state that is conducive for beam splitting. Figure 3a shows the birefringence in the proposed PCF with and without the $\mathrm{As}_{2} \mathrm{~S}_{3}$ layer. Generally, birefringence [36] can be defined by:

$$
B=\left|n_{e f f}^{x}-n_{e f f}^{y}\right|
$$

where $n_{\text {eff }}^{x}$ and $n_{\text {eff }}^{y}$ represent the effective RI for the x- and y-pol modes, respectively; they can be solved based on Maxwell's equations. From Figure 3a, we can observe that birefringence of the proposed PBS was higher than that of the PBS without the $\mathrm{As}_{2} \mathrm{~S}_{3}$ layer. Thus, the proposed PBS had a better splitter effect.

The coupling length can determine the minimum size of a splitter device. According to the report of [14], the choice of the CLR = 2 was conducive to the design of the proposed PCF-PBS because the desired PCF would have a better tolerance to the variation of structural parameters. For PBSs with other kinds of CLRs, when the PCF's structural parameters change, the device length has larger variations. It is generally difficult to achieve these variations. For simplicity, we supposed the relationship of $L_{x}>L_{y}$, and the dual-core PCF with $L_{x} / L_{y}=2$ at $1.55 \mu \mathrm{m}$ was able to be achieved for the PBS. We set the PCF length to $L_{x}$, which is the minimum coupling length.

For the CLR, the effect of the characteristic parameters-including the relative diameter ratio $\alpha$, the lattice pitch $\Lambda$, and the thickness of the $\mathrm{As}_{2} \mathrm{~S}_{3}$ layer $t$-was considered. The propagating constants of the even and odd modes of the $x$ - and $y$-pol lights in the dual-core PCF were obtained from FEM calculation, and then the corresponding coupling lengths were calculated with Equation (3). Finally, the CLR could be deduced. According to Figure $3 b-d$, when the conditions of $\Lambda=2.2 \mu \mathrm{m}, d_{1}=1.1 \mu \mathrm{m}$, $d_{2}=2.2 \mu \mathrm{m}$, and $t=150 \mathrm{~nm}$ were simultaneously satisfied, the desired CLR could be achieved. It can be observed from Figure $3 b$ that when the normalized pitch $\Lambda / \lambda$ was small, the coupling length increased as the normalized pitch increased. However, after the CLR reached the maximum value of 2 (here $\Lambda=$ $2.2 \mu \mathrm{m})$, the CLR decreased with the increase in the normalized pitch. When a variation of $\pm 3 \%$ of $\Lambda$ was considered, the corresponding CLR fluctuated around 2, but this fluctuation will be gradually reduced as technology advances and precise structural tailoring can be achieved. Figure $3 \mathrm{c}$ displays the effect of the relative diameter ratio on the CLR. When the relative diameter ratio $\alpha=d_{2} / d_{1}=2$, the coupling length ratio was exactly 2. The perturbation effect of the variation of $\pm 3 \%$ of $d_{2}$ could be ignored. Finally, as shown in Figure 3d, when the $\mathrm{As}_{2} \mathrm{~S}_{3}$ layer thickness was exactly $150 \mathrm{~nm}$, the coupling length ratio was exactly 2 . The variation of $\pm 3 \%$ of $t$ caused the CLR curve to translate, but the maximum value was almost unchanged, thus showing a good fabrication tolerance.

Thus, considering the cases of birefringence and the CLR of 2 in the PCF, these structural parameters of $\Lambda=2.2 \mu \mathrm{m}, d_{1}=1.1 \mu \mathrm{m}, d_{2}=2.2 \mu \mathrm{m}$, and $t=150 \mathrm{~nm}$ were suitable for the design of the desired PBS. 

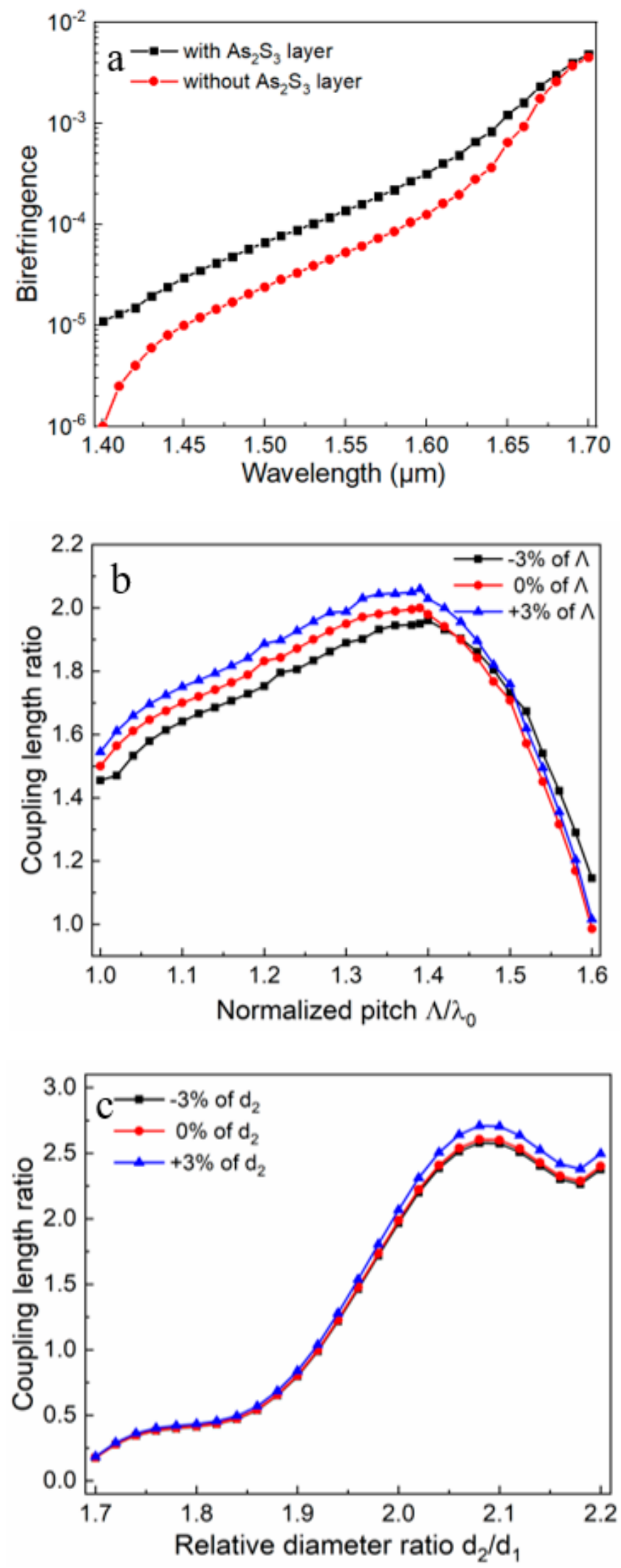

Figure 3. Cont. 


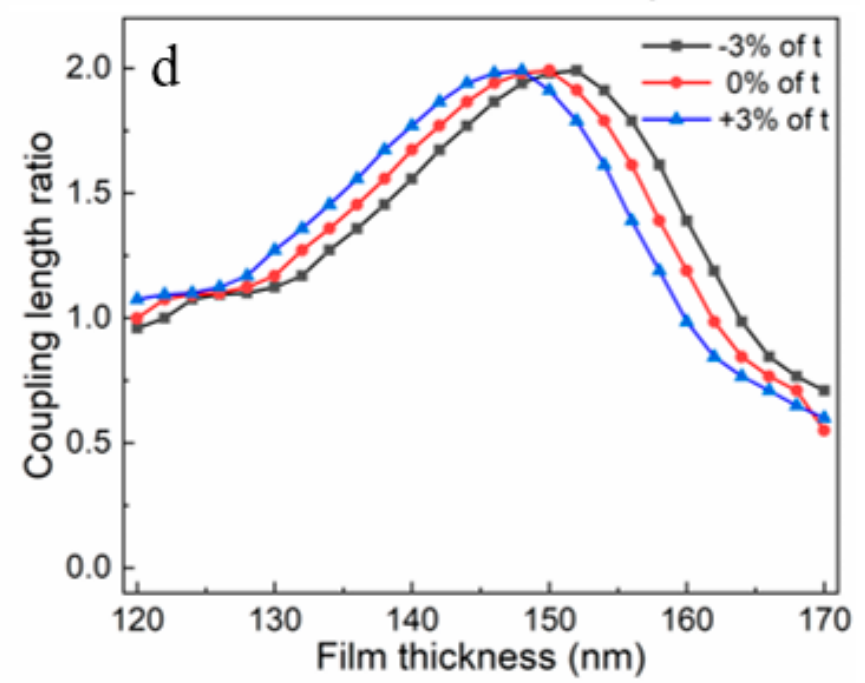

Figure 3. (a) Birefringence in the proposed PCF-PBS with and without the $\mathrm{As}_{2} \mathrm{~S}_{3}$ layer, as well as the effect of different PCF characteristic parameters on the coupling length ratio (CLR) for the proposed PBS. (b) The CLR versus normalized pitch when $d_{1}=1.1 \mu \mathrm{m}, d_{2}=2.2 \mu \mathrm{m}$, and $t=150 \mathrm{~nm}$; (c) the CLR versus the relative diameter ratio when $\Lambda=2.2 \mu \mathrm{m}, d_{1}=1.1 \mu \mathrm{m}$, and $t=150 \mathrm{~nm}$; and (d) the CLR versus the $\mathrm{As}_{2} \mathrm{~S}_{3}$ layer thickness when $\Lambda=2.2 \mu \mathrm{m}, d_{1}=1.1 \mu \mathrm{m}$, and $d_{2}=2.2 \mu \mathrm{m}$.

\subsection{Normalized Power, Extinction Ratio, and Insertion Loss}

The normalized power of the $\mathrm{x}-$ and $\mathrm{y}$-pol lights in cores A and B for the proposed PCF-PBS regularly changed with the propagation distance. When an incident light travelled a certain distance, the intensity of the polarized light in a certain core was at a maximum value, the intensity of the other polarized light in the corresponding vertical direction was at a minimum value, and two polarized lights were split out. The normalized power also helped us determine the minimum size of the PBS, as shown in Figure 4a. We found that when the length of the PBS was $1.0 \mathrm{~mm}$, only the y-pol and x-pol lights were sustained in cores A and B, respectively, and the separation of the $\mathrm{x}$ - and y-pol lights was achieved. We also studied the normalized power of the same structured PBS without the $\mathrm{As}_{2} \mathrm{~S}_{3}$ layer. Figure $4 \mathrm{~b}$ shows that the coupling length achieved by the FEM method was approximately $4.5 \mathrm{~mm}$. Therefore, in terms of compactness, the proposed PBS with the $\mathrm{As}_{2} \mathrm{~S}_{3}$ layer was better.

The ER is an important parameter reflecting performance of PBS, and it was employed to describe the degree of polarization separation [37]. $P_{x}^{A}$ and $P_{y}^{A}$ represent the power of the $\mathrm{x}$ - and y-pol lights in core A, respectively. For core A, the ER can be defined by:

$$
E R(d B)=10 \log _{10}\left(P_{x}^{A} / P_{y}^{A}\right)
$$

The higher the ER is, the better the performance of a PBS is. In practical applications, when the ER reaches $-20 \mathrm{~dB}$, the power of one polarized light is 100 times than that of the other polarized light, which is enough to split out the two polarized lights. We regarded the wavelength range corresponding to the extinction ratio of less than or equal to $-20 \mathrm{~dB}$ as the bandwidth of this PBS. Figure 5 shows the ERs in cores A and B at the $1.55 \mu \mathrm{m}$ wavelength. As shown in Figure $5 \mathrm{a}$, the minimum ER could reach $-83.6 \mathrm{~dB}$, and the bandwidth at $280 \mathrm{~nm}$ ranged from 1.45 to $1.73 \mu \mathrm{m}$ in core A for the proposed PBS. For core $\mathrm{B}$, its minimum ER could reach $-49 \mathrm{~dB}$, of which the bandwidth with the extinction ratio less than $20 \mathrm{~dB}$ at $160 \mathrm{~nm}$ ranged from 1.46 to $1.62 \mu \mathrm{m}$. Compared with the proposed PBS, the PBS without the $\mathrm{As}_{2} \mathrm{~S}_{3}$ layer had a lower ER and a narrower bandwidth. Core A had a minimum ER of $-48.1 \mathrm{~dB}$ and a bandwidth of $60 \mathrm{~nm}$. Core B had a minimum ER of $-39.3 \mathrm{~dB}$ and a bandwidth of $55 \mathrm{~nm}$. These results illustrate that the proposed PCF-PBS had a sufficient ER and a broad bandwidth, and it could stably separate polarized light in the vicinity of $1.55 \mu \mathrm{m}$. 

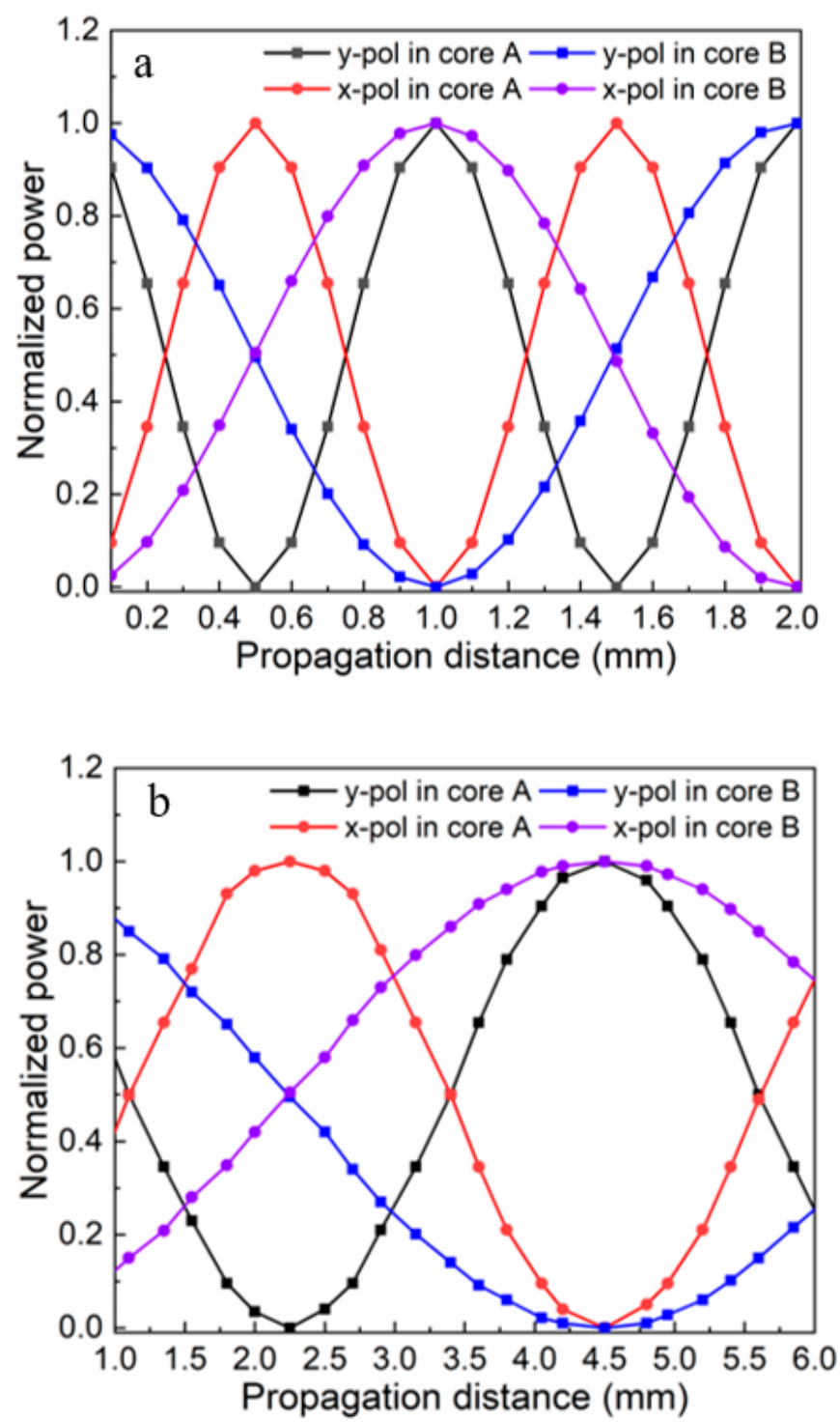

Figure 4. Various energy transfer values in cores A and B for the proposed PCF-PBS (a) with the $\mathrm{As}_{2} \mathrm{~S}_{3}$ layer and (b) without the $\mathrm{As}_{2} \mathrm{~S}_{3}$ layer versus the propagation distance when $\Lambda=2.2 \mu \mathrm{m}, d_{1}=1.1 \mu \mathrm{m}$, $d_{2}=2.2 \mu \mathrm{m}$, and $t=150 \mathrm{~nm}$.

Because it is an optical communication device, the IL of the proposed PBS had to be analyzed. Generally, the restriction of light in the core was not perfect, and the IL was one of the potential losses that caused this phenomenon [38]. The IL of the proposed PBS relied on the energy transfer ratio between the two cores and the absorption loss of the $\mathrm{As}_{2} \mathrm{~S}_{3}$ layer. Here, the absorption loss of the $\mathrm{As}_{2} \mathrm{~S}_{3}$ layer was negligible. Therefore, the IL $[39,40]$ could be defined by:

$$
I L(d B)=-10 \log _{10}\left(\frac{P_{\text {out }}}{P_{\text {in }}}\right)
$$

where $P_{\text {in }}$ and $P_{\text {out }}$ denote the input power and output power in a core, respectively. For a PBS, the IL should be as small as possible to ensure strong performance. Figure 6 shows various insertion loss values of the $x$ - and $y$-pol lights for the proposed PCF-PBS with the $\mathrm{As}_{2} \mathrm{~S}_{3}$ layer (Figure 6a) and without the $\mathrm{As}_{2} \mathrm{~S}_{3}$ layer (Figure $6 \mathrm{~b}$ ) versus wavelength. At the communication window of $1.55 \mu \mathrm{m}$, both the $\mathrm{x}-$ and y-pol lights had similar IL trends. For the proposed PCF-PBS, the IL was $0.18 \mathrm{~dB}$ for the x-pol light 
and $1.1 \mathrm{~dB}$ for the y-pol light. For the PBS without the $\mathrm{As}_{2} \mathrm{~S}_{3}$ layer, the IL was $0.55 \mathrm{~dB}$ for the $\mathrm{x}$-pol light and $1.35 \mathrm{~dB}$ for the y-pol light. Obviously, the proposed PBS had an advantage regarding the IL.
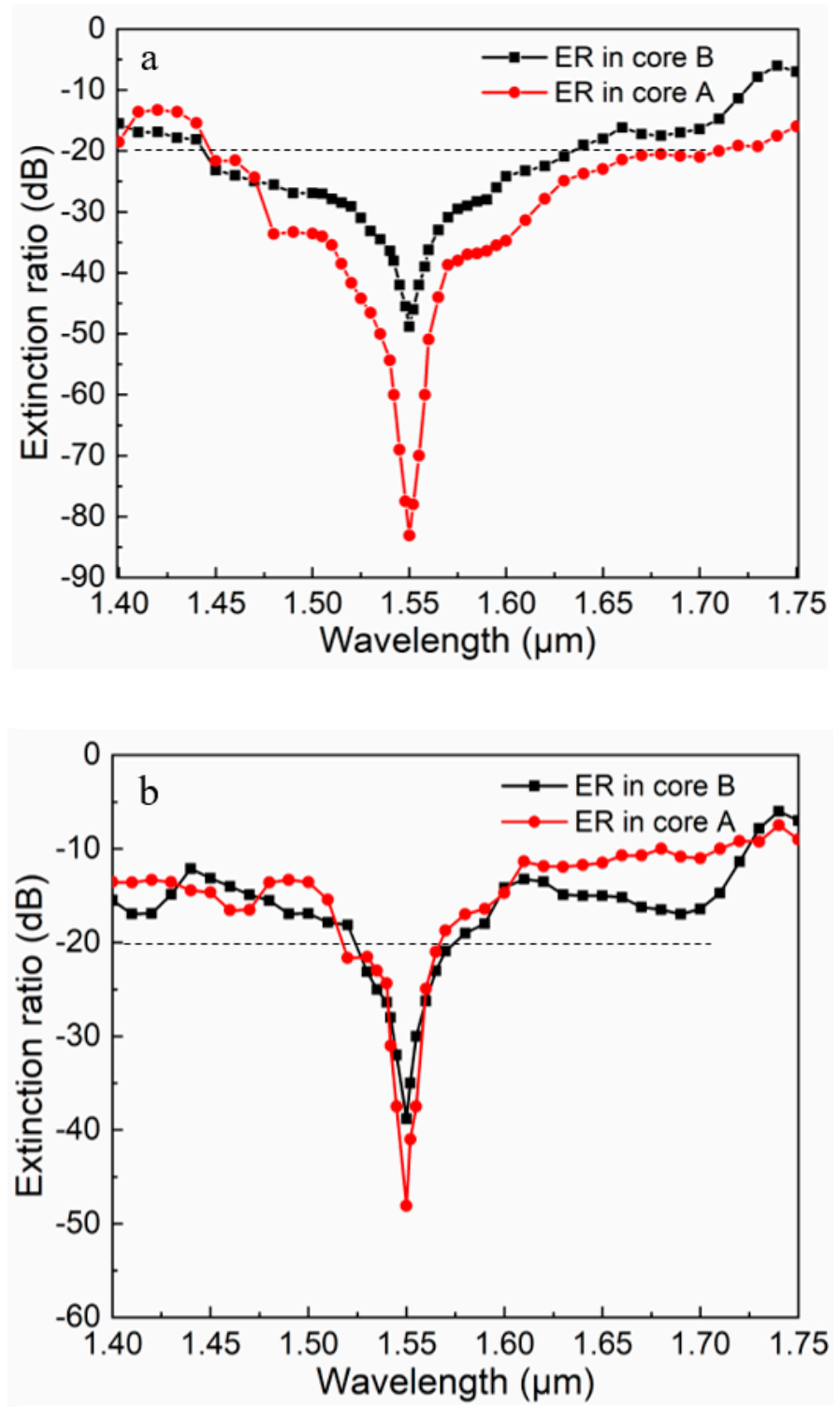

Figure 5. Various extinction ratios (ERs) of the $x$ - and y-pol lights for the proposed PCF-PBS (a) with the $\mathrm{As}_{2} \mathrm{~S}_{3}$ layer and $(\mathbf{b})$ without the $\mathrm{As}_{2} \mathrm{~S}_{3}$ layer versus wavelength when $\Lambda=2.2 \mu \mathrm{m}, d_{1}=1.1 \mu \mathrm{m}, d_{2}=$ $2.2 \mu \mathrm{m}$, and $t=150 \mathrm{~nm}$. 

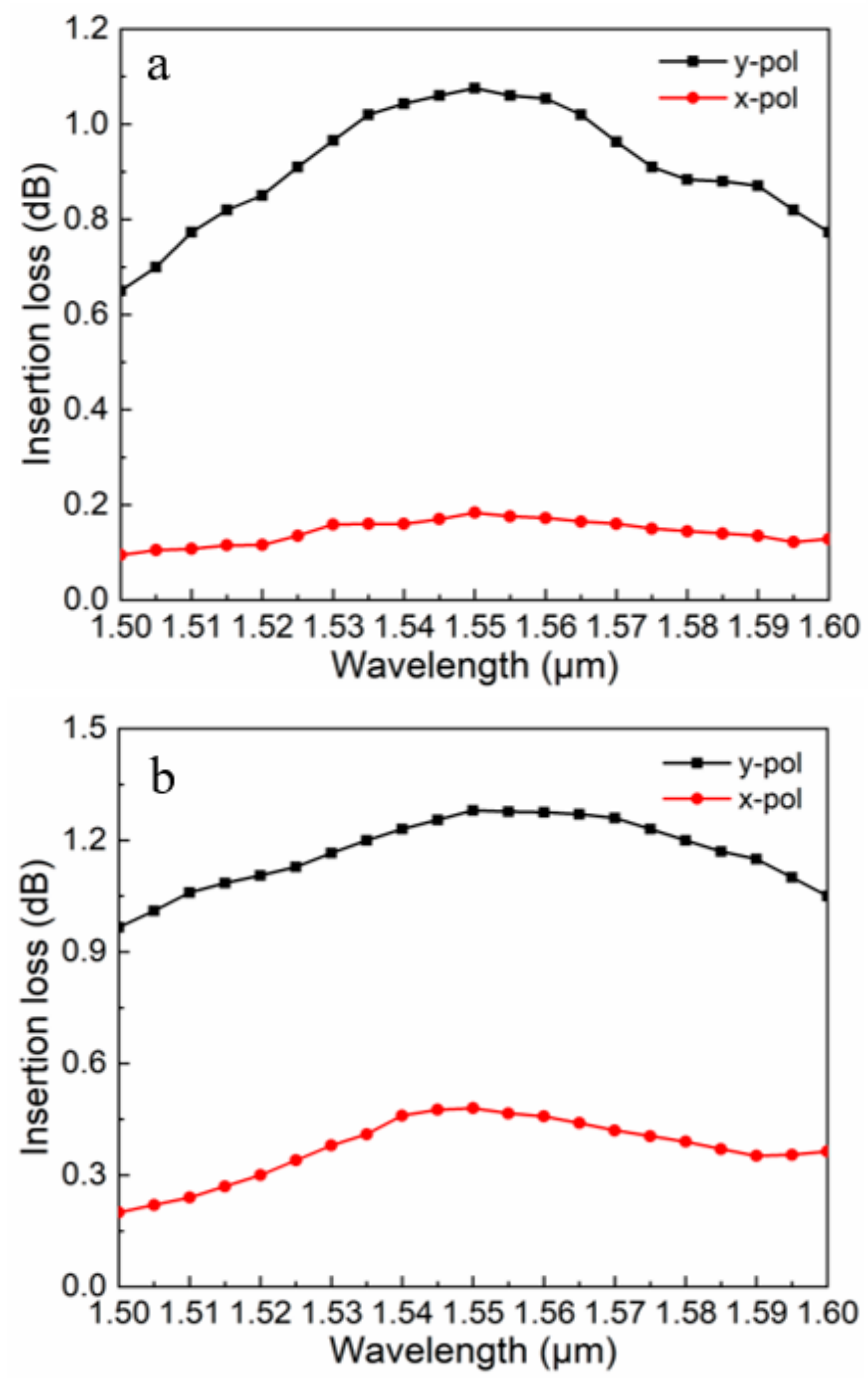

Figure 6. Various insertion loss (IL) values of the $x$ - and y-pol lights for the proposed PCF-PBS (a) with the $\mathrm{As}_{2} \mathrm{~S}_{3}$ layer and $(\mathbf{b})$ without the $\mathrm{As}_{2} \mathrm{~S}_{3}$ layer versus wavelength when $\Lambda=2.2 \mu \mathrm{m}, d_{1}=1.1 \mu \mathrm{m}, d_{2}=$ $2.2 \mu \mathrm{m}$, and $t=150 \mathrm{~nm}$.

To characterize the performance of the proposed PBS, several key parameters-device size, the ER, bandwidth, and IL-were investigated. Based on the results described above, it can obviously be seen that the performance of the proposed PBS was superior to that of the PBS without the $\mathrm{As}_{2} \mathrm{~S}_{3}$ layer.

Additionally, the key performance characteristics of the proposed PCF-PBS and prior PBSs are listed in Table 1 for comparison. From the comparison results, it can be observed that the proposed PBS possessed a compact size, a higher ER, a lower IL, and a broader bandwidth than that of most other PBSs. Though the three PBSs from the literature [41-43] had particularly broad bandwidths, they were far less compact than ours. Considering that there are not many PBSs that simultaneous achieve excellent performance for the four parameters, the proposed PBS still has performance advantages and shows great application potential. 
Table 1. Comparison results between the proposed PBS and prior PBSs.

\begin{tabular}{ccccc}
\hline Ref & Device Length $(\mathbf{m m})$ & ER $(\mathbf{d B})$ & Bandwidth $(\mathbf{n m})$ & IL $(\mathbf{d B})$ \\
\hline$[13]$ & 8.7983 & -164.2681 & 20 & N/A \\
{$[14]$} & $\sim 6$ & -40 & 146 & N/A \\
{$[15]$} & 0.09 & -80.7 & 250 & N/A \\
{$[16]$} & 0.401 & -110 & 140 & N/A \\
{$[17]$} & 8.13 & $>-100$ & $\sim 20$ & N/A \\
{$[18]$} & 5.678 & -30 & 3 & N/A \\
{$[31]$} & 2 & -52.5 & 100 & N/A \\
{$[33]$} & 0.3 & 23 & $\sim 20$ & N/A \\
{$[41]$} & 84.7 & -30 & 300 & N/A \\
{$[42]$} & 52.8 & $\sim 50$ & 320 & N/A \\
{$[43]$} & 72.5 & $\sim 50$ & 400 & N/A \\
{$[44]$} & 1.9 & $\sim-35$ & 37 & N/A \\
{$[45]$} & 1.9207 & -65 & 226 & 0.42737 \\
{$[46]$} & 0.103 & -72 & 177 & 0.00013 \\
{$[47]$} & 0.078 & 87 & $40(>15 \mathrm{~dB})$ & N/A \\
The paper & 1.0 & -83.6 & 280 & 0.18 \\
\hline
\end{tabular}

\section{Fabrication Discussion}

Additionally, we took the fabrication of the proposed PCF-PBS into account.

The stack-and-draw technique $[48,49]$ can be utilized to fabricate the proposed PCF. For rod stacking, different dimensions of FP glass rods corresponding to the number of cladding holes were stacked into a preform, as shown in Figure 1a. During the drawing process, the preform was drawn into a PCF with the desired dimensions by precisely controlling drawing parameters such as the heat temperature, drawing and perform feed speed, and nitrogen $\left(\mathrm{N}_{2}\right)$ content. In order to ensure the quality of the PCF, the preform surface treatment steps need to be continuously implemented [50].

Next was the integration of the $\mathrm{As}_{2} \mathrm{~S}_{3}$ films into the proposed PCF's central hole. Markos et al. proposed a new fabrication technique for all-fiber nonlinear tunable devices. We adopted such a method to deposit the $\mathrm{As}_{2} \mathrm{~S}_{3}$ layer on the inner wall of the central hole. A piece of the proposed PCF was cleaved for filling. Firstly, we dissolved the $\mathrm{As}_{2} \mathrm{~S}_{3}$ in an amine solvent. Secondly, to ensure that the solution could pass through the PCF's central hole, we sealed the air holes in the cladding. except for the central hole, with a UV-curable polymer [51]. Thirdly, we filled the nanogel-like solution into central hole of the PCF via capillary absorption. The filled PCF was placed in an oven at $50{ }^{\circ} \mathrm{C}$ for solvent evaporation, and then an amorphous $\mathrm{As}_{2} \mathrm{~S}_{3}$ layer was formed in the central hole. Using the annealing process, the optical properties of the PCF with the $\mathrm{As}_{2} \mathrm{~S}_{3}$ layer could be adjusted. The thickness of the $\mathrm{As}_{2} \mathrm{~S}_{3}$ layer could be monitored by SEM [52,53]. Finally, the end of the PCF blocked by the glue was cleaved off. Using a similar method, the tunable PCF filters and sensing elements based on $\mathrm{As}_{2} \mathrm{~S}_{3}$ could also be completely fabricated [54].

Therefore, we believe that the proposed PCF-PBS can be completely manufactured with the support of the described processing techniques.

\section{Conclusions}

In this work, a compact, dual-core PCF-PBS based on a thin $\mathrm{As}_{2} \mathrm{~S}_{3}$ film was proposed and numerically demonstrated. When the structural parameters were $d_{1}=1.1 \mu \mathrm{m}, d_{2}=2.2 \mu \mathrm{m}, t=150 \mathrm{~nm}$, and $\Lambda=2.2 \mu \mathrm{m}$, the relation of $L_{x} / L_{y}=2$ could be satisfied at $1.55 \mu \mathrm{m}$, which is suitable to design PBSs. Our numerical results showed that the performance of the reported PBS was obviously better than that of a non- $\mathrm{As}_{2} \mathrm{~S}_{3}$ PBS with same structure. When the coupling length of the reported PCF-PBS was $1.0 \mathrm{~mm}$, for core $\mathrm{A}$, the ER could reach $-83.6 \mathrm{~dB}$, and the bandwidth of the ER better than $-20 \mathrm{~dB}$ was $280 \mathrm{~nm}$; for core $\mathrm{B}$, the ER could reach $-49 \mathrm{~dB}$, and the bandwidth of the ER better than $-20 \mathrm{~dB}$ was $160 \mathrm{~nm}$. It also had a low IL of $0.18 \mathrm{~dB}$ for the x-pol light. Additionally, the proposed PCF-PBS 
can be completely manufactured by existing processes. This work will help to provide a new idea for designing a dual-core PCF-PBS with a compact size, a high ER, a broad bandwidth, and a low IL. The proposed PBS shows broad application prospects in the communication, sensing, and optical measurement fields.

Future work should conduct the experimental verification of our numerical results. The most direct method of doing this is splicing the PBS to a standard SMF and then launching an incident light into it $[55,56]$. We plan to build a simple experimental setup to observe the optical characterization of the proposed PBS. Then, we will connect a high power super-continuum source (480-2200 nm), a piece of spliced PCF, an optical separator, a charge-coupled device (CCD) camera, and an optical spectrum analyzer (OSA) in turn. At last, we will compare the collected data of the OSA with the simulation results.

Author Contributions: Conceptualization, N.C. and M.C.; methodology, N.C.; software, N.C.; validation, N.C., X.L. and M.C.; formal analysis, X.L.; investigation, N.C.; X.L.; Z.Z. and Z.M.; resources, X.Z.; data curation, M.C.; writing - original draft preparation, N.C.; writing-review and editing, N.C. and M.C.; visualization, J.Z. and N.C.; supervision, X.Z.; project administration, X.Z.; funding acquisition, X.Z. All authors have read and agreed to the published version of the manuscript.

Funding: This work was financially supported from National Key Scientific Apparatus Development of Special Item of China (Project Number: 2016YFF0101400).

Acknowledgments: Sincerely thanks Xiaoli Xu in University of Shanghai for Science and Technology and Lei Xu in Fudan University for their kindly discussion with authors.

Conflicts of Interest: All authors declare no potential conflict of interest.

\section{References}

1. Tyan, R.-C.; Salvekar, A.A.; Chou, H.-P.; Cheng, C.-C.; Scherer, A.; Sun, P.-C.; Xu, F.; Fainman, Y. Design, fabrication, and characterization of form-birefringent multilayer polarizing beam splitter. J. Opt. Soc. Am. A 1997, 14, 1627. [CrossRef]

2. Azzam, R.M.A. Infrared Brewster-angle polarizing beam splitter using a high-index prism with a small wedge angle. Appl. Opt. 2017, 56, 3020-3021. [CrossRef]

3. Zheng, J.; Ye, Z.-C.; Sun, N.-L.; Zhang, R.; Sheng, Z.-M.; Shieh, H.-P.D.; Zhang, J. Highly anisotropic metasurface: A polarized beam splitter and hologram. Sci. Rep. 2014, 4, 6491. [CrossRef] [PubMed]

4. Ovchinnikov, Y.B. A planar waveguide beam splitter. Opt. Commun. 2003, 220, 229-235. [CrossRef]

5. Turner, M.D.; Saba, M.; Zhang, Q.; Cumming, B.; Schröder-Turk, G.E.; Gu, M. Miniature chiral beamsplitter based on gyroid photonic crystals. Nat. Photonics 2013, 7, 801-805. [CrossRef]

6. Bricheno, T.; Baker, V. All-fibre polarisation splitter/combiner. Electron. Lett. 1985, 21, 251. [CrossRef]

7. Russell, P. Crystal Fibers. J. Lightwave Technol. 2009, 24, 4729-4749. [CrossRef]

8. Russell, P.W. Photonic crystal fibers. Science 2003, 299, 358-362. [CrossRef]

9. Chremmos, I.D.; Kakarantzas, G.; Uzunoglu, N.K. Modeling of a highly nonlinear chalcogenide dual-core photonic crystal fiber coupler. Opt. Commun. 2005, 251, 339-345. [CrossRef]

10. Markos, C.; Yuan, W.; Vlachos, K.; Town, G.; Bang, O. Label-free biosensing with high sensitivity in dual-core microstructured polymer optical fibers. Opt. Express 2011, 19, 7790-7798. [CrossRef]

11. Hameed, M.F.O.; Obayya, S.S.A. Polarization splitter based on soft glass nematic liquid crystal photonic crystal fiber. IEEE Photonics J. 2009, 1, 265-276. [CrossRef]

12. Zhang, S.; Zhang, W.; Geng, P.; Li, X.; Ruan, J. Design of single-polarization wavelength splitter based on photonic crystal fiber. Appl. Opt. 2011, 50, 6576-6582. [CrossRef] [PubMed]

13. Liu, S.; Li, S.; Yin, G.-B.; Feng, R.-P.; Wang, X.-Y. A novel polarization splitter in ZnTe tellurite glass three-core photonic crystal fiber. Opt. Commun. 2012, 285, 1097-1102. [CrossRef]

14. Sun, B.; Chen, M.-Y.; Zhou, J.; Zhang, Y.-K. Surface Plasmon Induced Polarization Splitting Based on Dual-Core Photonic Crystal Fiber with Metal Wire. Plasmonics 2013, 8, 1253-1258. [CrossRef]

15. Chen, H.L.; Li, S.G.; Fan, Z.K.; An, G.W.; Li, J.S.; Han, Y. A Novel Polarization Splitter Based on Dual-Core Photonic Crystal Fiber with a Liquid Crystal Modulation Core. IEEE Photonics J. 2014, 6, 1-9. [CrossRef] 
16. Xu, Z.; Li, X.; Ling, W.; Liu, P.; Zhang, Z. Design of short polarization splitter based on dual-core photonic crystal fiber with ultra-high extinction ratio. Opt. Commun. 2015, 354, 314-320. [CrossRef]

17. Wang, J.; Pei, L.; Weng, S.; Wu, L.; Huang, L.; Ning, T.; Li, J. A Tunable Polarization Beam Splitter Based on Magnetic Fluids-Filled Dual-Core Photonic Crystal Fiber. IEEE Photonics J. 2017, 9, 1-10. [CrossRef]

18. Younis, B.M.; Heikal, A.M.; Hameed, M.F.O.; Obayya, S.S.A. Highly wavelength-selective asymmetric dual-core liquid photonic crystal fiber polarization splitter. J. Opt. Soc. Am. B 2018, 35, 1020-1029. [CrossRef]

19. Cazorla, C.; Boronat, J. Simulation and understanding of atomic and molecular quantum crystals. Rev. Mod. Phys. 2017, 89, 1-54. [CrossRef]

20. Saitoh, K.; Koshiba, M. Numerical modeling of photonic crystal fibers. J. Light. Technol. 2005, 23, 3580-3590. [CrossRef]

21. Hameed, M.F.O.; Heikal, A.M.; Younis, B.M.; Abdelrazzak, M.; Obayya, S.S.A. Ultra-high tunable liquid crystal-plasmonic photonic crystal fiber polarization filter. Opt. Express 2015, 23, 7007-7020. [CrossRef] [PubMed]

22. Chen, N.; Chang, M.; Zhang, X.; Zhou, J.; Lu, X.; Zhuang, S. Highly Sensitive Plasmonic Sensor Based on a Dual-Side Polished Photonic Crystal Fiber for Component Content Sensing Applications. Nanomaterials 2019, 9, 1587. [CrossRef]

23. Zha, Y.; Waldmann, M.; Arnold, C.B. A review on solution processing of chalcogenide glasses for optical components. Opt. Mater. Express 2013, 3, 1259. [CrossRef]

24. Saghaei, H.; Heidari, V.; Ebnali-Heidari, M.; Yazdani, M.R. A systematic study of linear and nonlinear properties of photonic crystal fibers. Optik 2016, 127, 11938-11947. [CrossRef]

25. Saitoh, K.; Koshiba, M.; Hasegawa, T.; Sasaoka, E. Chromatic dispersion control in photonic crystal fibers: Application to ultra-flattened dispersion. Opt. Express 2003, 11, 843-852. [CrossRef] [PubMed]

26. Snyder, A.W. Coupled-Mode Theory for Optical Fibers. J. Opt. Soc. Am. 1972, 62, 1267. [CrossRef]

27. Nagasaki, A.; Saitoh, K.; Koshiba, M. Polarization characteristics of photonic crystal fibers selectively filled with metal wires into cladding air holes. Opt. Express 2011, 19, 3799-3808. [CrossRef]

28. An, G.; Li, S.; Yan, X.; Yuan, Z.; Zhang, X. High-birefringence photonic crystal fiber polarization filter based on surface plasmon resonance. Appl. Opt. 2016, 55, 1262-1266. [CrossRef] [PubMed]

29. Liu, Q.; Li, S.; Li, H.; Zi, J.; Zhang, W.; Fan, Z.; An, G.; Bao, Y. Broadband Single-Polarization Photonic Crystal Fiber Based on Surface Plasmon Resonance for Polarization Filter. Plasmonics 2015, 10, 931-939. [CrossRef]

30. Dash, J.N.; Jha, R. SPR Biosensor Based on Polymer PCF Coated with Conducting Metal Oxide. IEEE Photonics Technol. Lett. 2014, 26, 595-598. [CrossRef]

31. Liu, Q.; Li, S.; Chen, H. Two Kinds of Polarization Filter Based on Photonic Crystal Fiber with Nanoscale Gold Film. IEEE Photonics J. 2015, 7, 1-11. [CrossRef]

32. Wang, J.; Pei, L.; Weng, S.; Wu, L.; Huang, L.; Ning, T.; Li, J. Magneto-Modulating Polarization Converter Based on a Dual-Core Photonic Crystal Fiber. J. Light. Technol. 2017, 35, 2772-2777. [CrossRef]

33. Xue, J.; Li, S.; Xiao, Y.; Qin, W.; Xin, X.; Zhu, X. Polarization filter characters of the gold-coated and the liquid filled photonic crystal fiber based on surface plasmon resonance. Opt. Express 2013, 21, 13733-13740. [CrossRef] [PubMed]

34. Chen, N.; Chang, M.; Lu, X.; Zhou, J.; Zhang, X. Photonic Crystal Fiber Plasmonic Sensor Based on Dual Optofluidic Channel. Sensors 2019, 19, 5150. [CrossRef] [PubMed]

35. Chen, N.; Zhang, X.; Chang, M.; Lu, X.; Zhou, J. Broadband Plasmonic Polarization Filter Based on Photonic Crystal Fiber with Dual-Ring Gold Layer. Micromachines 2020, 11, 470. [CrossRef] [PubMed]

36. Rajeswari, D.; Raja, A.S.; Selvendran, S. Design and analysis of polarization splitter based on dual-core photonic crystal fiber. Optik 2017, 144, 15-21. [CrossRef]

37. Li, J.; Wang, J.; Wang, R.; Liu, Y. A novel polarization splitter based on dual-core hybrid photonic crystal fibers. Opt. Laser Technol. 2011, 43, 795-800. [CrossRef]

38. Khaleque, A.; Mironov, E.G.; Hattori, H.T. Analysis of the properties of a dual-core plasmonic photonic crystal fiber polarization splitter. Appl. Phys. A 2015, 121, 523-532. [CrossRef]

39. Chiang, J.-S.; Sun, N.-H.; Lin, S.-C.; Liu, W.-F. Analysis of an Ultrashort PCF-Based Polarization Splitter. J. Light. Technol. 2009, 28, 707-713. [CrossRef]

40. Soldano, L.; De Vreede, A.; Smit, M.; Verbeek, B.; Metaal, E.; Green, F. Mach-Zehnder interferometer polarization splitter in InGaAsP/InP. IEEE Photonics Technol. Lett. 1994, 6, 402-405. [CrossRef] 
41. Lu, W.; Lou, S.; Wang, X. Ultrabroadband polarization splitter based on a modified three-core photonic crystal fiber. Appl. Opt. 2013, 52, 8494-8500. [CrossRef] [PubMed]

42. Zhao, T.; Lou, S.; Wang, X.; Zhou, M.; Lian, Z. Ultrabroadband polarization splitter based on three-core photonic crystal fiber with a modulation core. Appl. Opt. 2016, 55, 6428-6434. [CrossRef] [PubMed]

43. Lu, W.; Lou, S.; Wang, X.; Wang, L.; Feng, R. Ultrabroadband polarization splitter based on three-core photonic crystal fibers. Appl. Opt. 2013, 52, 449-455. [CrossRef] [PubMed]

44. Saitoh, K.; Sato, Y.; Koshiba, M. Polarization splitter in three-core photonic crystal fibers. Opt. Express 2004, 12, 3940-3946. [CrossRef]

45. Liu, Q.; Li, S.; Wang, X.; Shi, M. Theoretical simulation of a polarization splitter based on dual-core soft glass PCF with micron-scale gold wire. Chin. Phys. B 2016, 25, 124210. [CrossRef]

46. Dou, C.; Jing, X.; Li, S.; Wu, J.; Wang, Q. A compact and low-loss polarization splitter based on dual-core photonic crystal fiber. Opt. Quantum Electron. 2018, 50, 255. [CrossRef]

47. Wang, J.; Pei, L.; Weng, S.; Wu, L.; Li, J.; Ning, T. Ultrashort polarization beam splitter based on liquid-filled dual-core photonic crystal fiber. Appl. Opt. 2018, 57, 3847-3852. [CrossRef]

48. Chillcce, E.F.; Cordeiro, C.M.B.; Barbosa, L.; Cruz, C.H.D.B. Tellurite photonic crystal fiber made by a stack-and-draw technique. J. Non-Cryst. Solids 2006, 352, 3423-3428. [CrossRef]

49. Chen, N.; Zhang, X.; Nie, F.; Lu, X.; Chang, M. Dispersion-compensating photonic crystal fiber with wavelength tunability based on a modified dual concentric core structure. J. Mod. Opt. 2018, 65, 1459-1465. [CrossRef]

50. Kalnins, C.A.G.; Spooner, N.A.; Monro, T.M.; Ebendorff-Heidepriem, H. Surface Analysis and Treatment of Extruded Fluoride Phosphate Glass Preforms for Optical Fiber Fabrication. J. Am. Ceram. Soc. 2016, 99, 1874-1877. [CrossRef]

51. Wu, D.K.C.; Kuhlmey, B.; Eggleton, B.J. Ultrasensitive photonic crystal fiber refractive index sensor. Opt. Lett. 2009, 34, 322. [CrossRef] [PubMed]

52. Markos, C.; Yannopoulos, S.N.; Vlachos, K. Chalcogenide glass layers in silica photonic crystal fibers. Opt. Express 2012, 20, 14814-14824. [CrossRef] [PubMed]

53. Markos, C.; Kubat, I.; Bang, O. Hybrid polymer photonic crystal fiber with integrated chalcogenide glass nanofilms. Sci. Rep. 2014, 4, 6057. [CrossRef]

54. Markos, C. Thermo-tunable hybrid photonic crystal fiber based on solution-processed chalcogenide glass nanolayers. Sci. Rep. 2016, 6, 31711. [CrossRef] [PubMed]

55. Leon-Saval, S.; Birks, T.A.; Joly, N.Y.; George, A.K.; Wadsworth, W.; Kakarantzas, G.; Russell, P.S.J. Splice-free interfacing of photonic crystal fibers. Opt. Lett. 2005, 30, 1629-1631. [CrossRef] [PubMed]

56. Xiao, L.; Demokan, M.S.; Jin, W.; Wang, Y.; Zhao, C. Fusion Splicing Photonic Crystal Fibers and Conventional Single-Mode Fibers: Microhole Collapse Effect. J. Light. Technol. 2007, 25, 3563-3574. [CrossRef] 